\title{
Coordination of Fetal Facial Expressions after 36 weeks of Gestation
}

\author{
${ }^{1}$ Mohamed AM AboEllail, ${ }^{2}$ Kenji Kanenishi, ${ }^{3}$ Nobuhiro Mori, ${ }^{4}$ Toshiyuki Hata
}

\begin{abstract}
Aim: To assess the coordination in the frequency of fetal facial expressions and reproducibility of fetal facial expression counting in normal singleton pregnancies in the third trimester of pregnancy using four-dimensional (4D) ultrasound.
\end{abstract}

Methods: One hundred and eleven healthy fetuses between 30 and 40 weeks of gestation were examined using 4D ultrasound. The frequencies of 7 facial expressions during 15-minute recordings were assessed. The fetuses were further divided into three gestational age groups (25 fetuses at 30-31 weeks, 43 at 32-35 weeks, and 43 at $\geq 36$ weeks). Correlation analysis between each frequency and other fetal facial expressions in each gestational age group was performed to determine the change in the number of significant correlations with advancing gestation.

Results: Only two significant correlations were identified among 21 combinations of facial expressions at 30-31 and 32-35 weeks of gestation, whereas more frequent correlations (nine significant correlations) were noted at 36 to 40 weeks ( $p=$ 0.009 ). All fetal facial expressions showed intra- and inter-class correlation coefficients greater than 0.72 , with good intra- and inter-observer agreements.

Conclusion: Our results suggest that the coordination of different parts of the fetal brain controlling facial expressions become apparent after 36 weeks of gestation because of the mature development of the fetal brain and central nervous system. To the best of our knowledge, this is the first study on the reproducibility assessment of fetal facial expression counting using 4D ultrasound.

Keywords: Brain maturation, Coordination of fetal facial expressions, Reproducibility assessment, Third trimester of pregnancy, 4D ultrasound.

How to cite this article: AboEllail MAM, Kanenishi K, Mori N, Hata T. Coordination of Fetal Facial Expressions after 36 weeks of Gestation. Donald School J Ultrasound Obstet Gynecol 2018;12(3):156-161.

Source of support: Nil

Conflict of interest: None

\footnotetext{
${ }^{1,3}$ Assistant Professor, ${ }^{2}$ Associate Professor, ${ }^{4}$ Professor and Chairman

${ }^{1-4}$ Department of Perinatology and Gynecology, Kagawa University Graduate School of Medicine, Japan
}

Corresponding Author: Toshiyuki Hata, Professor and Chairman, Department of Perinatology and Gynecology, Kagawa University Graduate School of Medicine, Japan Phone: +81-(0)87-891-2174, e-mail: toshi28@med.kagawa-u. ac.jp

\section{INTRODUCTION}

Prechtl found that the maturation and development of the fetal brain and central nervous system (CNS) could be recognized by the evaluation of fetal behavioral patterns. ${ }^{1-3}$ The five major senses are present within the face. The fetal face mediates expressions that provide the international language of communication. Therefore, fetal facial movements can be considered as an indicator of brain functions and CNS. ${ }^{4}$ Fetal face examination can be very useful for neuroscientists to indicate the integrity of the functional development of the fetal brain and CNS.

Facial expression muscles are innervated by facial and trigeminal nerves, which start to appear at 10 to 11 weeks of gestation. ${ }^{4}$ The muscles themselves are formed at 16 weeks of gestation, ${ }^{5}$ and full evaluation of their actions can be done from 24 weeks when adipose tissue deposition starts and gradually continues until 36 weeks of gestation. ${ }^{6}$ Parallel to the anatomical development, functional development takes place in the form of coordination of different parts of the human brain. Such functional development continues in postnatal stages. The current study aims to evaluate fetal facial expressions and the coordination between them as a possible indicator of brain development late in the third trimester, and to assess intra- and inter-observer reproducibility of facial expression counting using four-dimensional (4D) ultrasound.

\section{METHODS}

The design of the study, a sample of patients, criteria for inclusion, and definitions offacial expressions are described in detail in our previous publication. ${ }^{7}$ One hundred and eleven healthy fetuses of healthy, middle class, non-smoker Japanese women with singleton pregnancies at 30 to 40 weeks were included in the study, which extended from April 2014 to April 2016. Smokers were excluded based on the questionnaire completed by the pregnant women during their first antenatal booking. High-risk pregnancies such as multiple pregnancies, hypertensive disorders of pregnancy, gestational diabetes, fetal growth restriction, threatened preterm labor, polyhydramnios and fetal abnormalitieswere excluded from the study. Gestational age was calculated from the first day of last menstrual period and confirmed by the first-trimester or early second-trimester sonographic 
examination. A 15-minute examination of seven facial expressions was conducted using 4D ultrasound (Voluson E8, GE Healthcare Japan, Tokyo, Japan) and a curved array transabdominal transducer (4-8.5 MHz) with a maximum frame rate of 40 frames/second.The region of interest was the sagittal section of the fetal face including the forehead, eyes, nose, and mouth to enable a clear assessment of the facial expressions. All 4D ultrasound examinations were performed by one experienced examiner (M.A.M.A.). The examinations were recorded on USB flash drive to enable accurate evaluation of the frequencies, and to allow reproducibility assessment. All pregnancies were examined once. The venue was a quiet, temperature-controlled room. Most of the examinations were done in the morning, and no acoustic or mechanical stimulation was used. As described in detail in our previous study, ${ }^{7}$ seven facial expressions (mouthing, yawning, smiling, tongue expulsion, scowling, sucking, and blinking) were assessed. The pregnant women were subdivided into three gestational age groups ( 30 to 32 weeks, 32 to 35 weeks, and $\geq 36$ weeks).The study was approved by the local Ethics Committee of Kagawa University Graduate School of Medicine, and standardized informed consent to participate in the study was obtained from each patient.

The correlation between the frequency of each facial expression and that of otherfacial expressions was assessed ateach gestational age group using Spearman's rank correlation coefficient. Comparison of the number of significant correlations among three gestational age groups was conducted with the chi-square test. Statistical analysis was conducted with IBM SPSS statistical software, version 22 for Windows (IBM SPSS Inc., Chicago, IL, USA). A value of $\mathrm{p}<0.05$ was considered significant.

Intra- and inter-class correlation coefficients were defined as the correlation between any two counts of each facial expression. Intra-observer (M.A.M.A.) and inter-observer (M.A.M.A. and N.M.) variabilities were shown according to Bland and Altman's procedure ${ }^{8}$ in 30 randomly selected subjects out of 111 .The $p<0.05$ value was considered significant. These 30 randomly selected videos were analyzed by M.A.M.A with a time interval of about one month to detect the intra-observer agreement. Regarding the inter-observer agreement, the two observers counted the frequencies of facial expressions in the same 30 selected videos blinded to each other.

\section{RESULTS}

\section{Intra- and Inter-observer Agreements}

Intra- and inter-class correlation coefficients for each fetal facial expression are shown in Tables 1 and 2 . The mean differences between measurements and the limits of agreement for each of the frequency of fetal facial expressions are also shown in Tables 1 and 2. No difference in the frequency of each fetal facial expression was significant.In this study, good intra- and inter-class correlation coefficients and intra- and inter-observer agreements were obtained. Therefore, the measurement values from only one examiner (M.A.M.A.) were used for statistical analysis.

At 30 to 31 weeks, mouthing showed a significant correlation with yawning and tongue expulsion ( $\mathrm{p}<$ 0.05). No significant correlation was found among other facial expressions (Table 3). However, at 32 to 35 weeks, a significant correlation was found between mouthing and smiling as well as between tongue expulsion and yawning (Table 4). The third gestational age group demonstrated multiple significant correlations (9 out of 21 combinations of fetal facial expressions) between facial expressions (Table 5). Mouthing was found to be correlated with yawning, tongue expulsion, and blinking. Yawing was correlated with sucking. Smiling showed a significant correlation with scowling, sucking, and blinking. Finally, tongue expulsion was correlated with scowling and sucking. Table 6 summarizes the correlations between different facial expressions in the three gestational age groups.

Table 1: Intra-class correlation coefficient and intra-observer agreement for fetal facial expressions

\begin{tabular}{lllllll}
\hline Fetal movement & Mean difference & $95 \% \mathrm{Cl}$ & $\begin{array}{l}\text { Limits of } \\
\text { agreement }\end{array}$ & p-value & ICC & $p$-value \\
\hline Mouthing & 0.266 & -1.454 & $-3.53-4.09$ & 0.459 & 0.91 & $<0.001$ \\
Yawning & 0.0667 & -0.2991 & $-1.07-1.20$ & 0.536 & 0.868 & $<0.001$ \\
Smiling & 0 & -0.338 & $-0.89-0.89$ & 1 & 0.973 & $<0.001$ \\
Tongue & -0.0667 & -0.336 & $-0.95-0.81$ & 0.423 & 0.924 & $<0.001$ \\
expulsion & & & & & \\
Scowling & -0.2 & -0.534 & $-1.6-1.19$ & 0.136 & 0.844 & $<0.001$ \\
Sucking & -0.1 & -0.494 & $-1.39-1.29$ & 0.415 & 0.822 & $<0.001$ \\
Blinking & -0.4 & -1.408 & $-4.09-3.65$ & 0.255 & 0.935 & $<0.001$ \\
\hline
\end{tabular}

$95 \% \mathrm{Cl}=95 \%$ confidence interval, ICC = intra-class correlation coefficient. 
Table 2: Inter-class correlation coefficient and inter-observer agreement for fetal facial expressions

\begin{tabular}{lllllll}
\hline Fetal movement & Mean difference & $95 \% \mathrm{Cl}$ & $\begin{array}{l}\text { Limits of } \\
\text { agreement }\end{array}$ & p-value & ICC & $p$-value \\
\hline Mouthing & 1.53 & $0.46-2.60$ & $-3.96-7.14$ & 0.006 & 0.862 & $<0.001$ \\
Yawning & -0.467 & $-1.14-0.13$ & $-2.07-1.14$ & 0.004 & 0.904 & $<0.001$ \\
Smiling & -0.033 & $-0.53-0.46$ & $-2.62-2.55$ & 0.61 & 0.891 & $<0.001$ \\
Tongue expulsion & 0.267 & $-0.01-0.54$ & $-1.18-1.72$ & 0.058 & 0.833 & 0.88 \\
Scowling & -0.50 & $-0.8-1.94$ & $-2.11-1.11$ & 0.002 & 0.72 & $<0.001$ \\
Sucking & 0.167 & $-0.19-0.52$ & $-1.7-2.03$ & 0.344 & 0.868 & $<0.001$ \\
Blinking & 1.87 & $0.70-3.03$ & $4.23-7.97$ & 0.003 & 0.001 \\
\hline
\end{tabular}

$95 \% \mathrm{Cl}=95 \%$ confidence interval, ICC = intrer-class correlation coefficient.

Table 3: Correlation between each frequency of fetal facial expression at 30-31 weeks

\begin{tabular}{|c|c|c|c|c|c|c|c|c|}
\hline $\begin{array}{l}\text { Facial } \\
\text { expression }\end{array}$ & & Mouthing & Yawning & Smiling & $\begin{array}{l}\text { Tongue } \\
\text { expulsion }\end{array}$ & Scowling & Sucking & Blinking \\
\hline Mouthing & $\begin{array}{l}\text { Correlation coefficient } \\
\text { Significance }\end{array}$ & - & $r=0.449$ & \multirow[b]{2}{*}{ NS } & $r=0.506$ & \multirow[b]{2}{*}{ NS } & \multirow[b]{2}{*}{ NS } & \multirow[b]{2}{*}{ NS } \\
\hline Yawning & $\begin{array}{l}\text { Correlation coefficent } \\
\text { Significance }\end{array}$ & - & $p=0.024$ & & $p=0.010$ & & & \\
\hline Smiling & $\begin{array}{l}\text { Correlation coefficient } \\
\text { Significance }\end{array}$ & - & - & - & NS & NS & NS & NS \\
\hline $\begin{array}{l}\text { Tongue } \\
\text { expulsion }\end{array}$ & $\begin{array}{l}\text { Correlation coefficient } \\
\text { Significance }\end{array}$ & - & - & - & - & NS & NS & NS \\
\hline Scowling & $\begin{array}{l}\text { Correlation coefficient } \\
\text { Significance }\end{array}$ & - & - & - & - & - & NS & NS \\
\hline Sucking & $\begin{array}{l}\text { Correlation coefficient } \\
\text { Significance }\end{array}$ & - & - & - & - & - & - & NS \\
\hline Blinking & $\begin{array}{l}\text { Correlation coefficient } \\
\text { Significance }\end{array}$ & - & - & - & - & - & - & - \\
\hline
\end{tabular}

NS, not significant.

\section{DISCUSSION}

The relationship between facial expressions and functional development of the brain throughout gestation was previously addressed in many studies using 4D ultrasound. ${ }^{9-18}$ However, a criticism applied to such kinds of neurobehavioral studies is the lack of standardization in methodology, which prevents the pooling of results. The advances in ultrasound machines with changes in frame rates per second and the variability in the duration of examinations represent obstacles. Moreover, the subjective judgments, which are influenced by the examiner's impressions, represent another important barrier. ${ }^{19,20}$ Therefore, the present study assessed interand intra-observer reproducibility of fetal facial expression counting evaluated by $4 \mathrm{D}$ ultrasound. Consequently, good intra- and inter-class correlation coefficients and intra- and inter-observer agreements were confirmed. To the best of our knowledge, this is the first study on the reproducibility assessment of fetal facial expression counting using 4D ultrasound. However, the data and their interpretation in the present study should be taken with some degree of caution because of the relatively small number of subjects studied. Further studies involving a larger sample size are needed to assess the exact reproducibility of fetal facial expression counting using $4 \mathrm{D}$ ultrasound.

In the current study, at 30 to 31 weeks as well as 32 to 35 weeks of gestation, there were only two significant correlations in 21 combinations of facial expressions. On the other hand, nine significant correlations out of the 21 combination s of facial expressions were found at 36 to 40 weeks. The human brain contains 10 billion neurons, a facial nerve is composed of approximately 10,000 neurons, and 7,000 of them are myelinated and innervate the nerves for facial expression. ${ }^{21}$ These neurons are connected to each other to coordinate their functions. With advancing gestation, the connections among fetal brain parts are progressively increasing, and towards the end of pregnancy, their number exceeds those present in the adult brain. ${ }^{22}$ Therefore, the increased coordination of fetal facial expressions after 36 weeks of gestation compared with 30 to 35 weeks' gestation might be a 
Table 4: Correlation between each frequency of fetal facial expression at 32-35 weeks

\begin{tabular}{|c|c|c|c|c|c|c|c|c|}
\hline $\begin{array}{l}\text { Facial } \\
\text { expression }\end{array}$ & & Mouthing & Yawning & Smiling & $\begin{array}{l}\text { Tongue } \\
\text { expulsion }\end{array}$ & Scowling & Sucking & Blinking \\
\hline Mouthing & $\begin{array}{l}\text { Correlation coefficient } \\
\text { Significance }\end{array}$ & - & NS & $\begin{array}{l}r=0.356 \\
p=0.019\end{array}$ & NS & NS & NS & NS \\
\hline Yawning & $\begin{array}{l}\text { Correlation coefficent } \\
\text { Significance }\end{array}$ & - & - & NS & $\begin{array}{l}r=0.489 \\
p=0.003\end{array}$ & NS & NS & NS \\
\hline Smiling & $\begin{array}{l}\text { Correlation coefficient } \\
\text { Significance }\end{array}$ & - & - & - & NS & NS & NS & NS \\
\hline $\begin{array}{l}\text { Tongue } \\
\text { expulsion }\end{array}$ & $\begin{array}{l}\text { Correlation coefficient } \\
\text { Significance }\end{array}$ & - & - & - & - & NS & NS & NS \\
\hline Scowling & $\begin{array}{l}\text { Correlation coefficient } \\
\text { Significance }\end{array}$ & - & - & - & - & - & NS & NS \\
\hline Sucking & $\begin{array}{l}\text { Correlation coefficient } \\
\text { Significance }\end{array}$ & - & - & - & - & - & - & NS \\
\hline Blinking & $\begin{array}{l}\text { Correlation coefficient } \\
\text { Significance }\end{array}$ & - & - & - & - & - & - & - \\
\hline
\end{tabular}

NS, not significant.

Table 5: Correlation between each frequency of fetal facial expression at 36-40 weeks

\begin{tabular}{|c|c|c|c|c|c|c|c|c|}
\hline $\begin{array}{l}\text { Facial } \\
\text { expression }\end{array}$ & & Mouthing & Yawning & Smiling & $\begin{array}{l}\text { Tongue } \\
\text { expulsion }\end{array}$ & Scowling & Sucking & Blinking \\
\hline Mouthing & $\begin{array}{l}\text { Correlation coefficient } \\
\text { Significance }\end{array}$ & - & $\begin{array}{l}r=0.303 \\
p=0.048\end{array}$ & NS & $\begin{array}{l}r=0.615 \\
p=0.00001\end{array}$ & NS & NS & $\begin{array}{l}r=0.395 \\
p=0.008\end{array}$ \\
\hline Yawning & $\begin{array}{l}\text { Correlation coefficent } \\
\text { Significance }\end{array}$ & - & - & NS & NS & NS & $\begin{array}{l}r=0.312 \\
p=0.042\end{array}$ & NS \\
\hline Smiling & $\begin{array}{l}\text { Correlation coefficient } \\
\text { Significance }\end{array}$ & - & - & - & $\begin{array}{l}r=0.374 \\
p=0.133\end{array}$ & $\begin{array}{l}r=0.307 \\
p=0.045\end{array}$ & $\begin{array}{l}r=0.351 \\
p=0.021\end{array}$ & NS \\
\hline $\begin{array}{l}\text { Tongue } \\
\text { expulsion }\end{array}$ & $\begin{array}{l}\text { Correlation coefficient } \\
\text { Significance }\end{array}$ & - & - & - & - & $\begin{array}{l}r=0.374 \\
p=0.0136\end{array}$ & $\begin{array}{l}r=0.533 \\
p= \\
0.0002\end{array}$ & NS \\
\hline Scowling & $\begin{array}{l}\text { Correlation coefficient } \\
\text { Significance }\end{array}$ & - & - & - & - & - & NS & NS \\
\hline Sucking & $\begin{array}{l}\text { Correlation coefficient } \\
\text { Significance }\end{array}$ & - & - & - & - & - & - & NS \\
\hline Blinking & $\begin{array}{l}\text { Correlation coefficient } \\
\text { Significance }\end{array}$ & - & - & - & - & - & - & - \\
\hline
\end{tabular}

NS, not significant.

reflection of the progressing, dense connections in the fetal brain.

Fetal neurobehavioral studies have identified the gradual development of coordinated motor activity, which eventually leads to the behavioral states described by Nijhuis et al. ${ }^{23}$ and Roodenberg et al. ${ }^{24}$ Rapid and slow eye movements become organized in episodes of activity and linked with other movements as breathing and the fetal heart rate at about 36 weeks of gestation. ${ }^{25}$ Horimoto et al. ${ }^{26}$ Confirmed the concurrence of regular mouthing and non-rapid eye movement at 36 weeks of gestation. Moreover, the switching and maintaining mechanisms responsible for alternating eye movement and non-eye movement periods become mature at that gestational age. ${ }^{27}$ In another study, there were significant differences in fetal breathing, head movement, limb movement,and mouthing at 36 weeks compared with earlier gestation. ${ }^{28}$
The same study demonstrated smoother movements following vibroacoustic stimulation at such an age, indicating a state of maturity of the fetal CNS. Towards 36 weeks of gestation, Reissland et al. ${ }^{29}$ reported the progression of increasingly complex fetal facial expressions compared with earlier third trimester and second trimester periods. Therefore, all this evidence supports our results showing that the coordination of different parts of the fetal brain controlling facial expressions become apparent after 36 weeks of gestation because of the mature development of the fetal brain and CNS.

There is a competitive process in the development of fetal brain connections, which results in the regression of certain pathways towards the end stages of fetal brain development and the appearance of other new connections. ${ }^{21}$ This election process involving the pathways of brain connectivity might explain the existence of different, 
Table 6: Change of correlation in the frequency of fetal facial expression with advancing gestation

\begin{tabular}{|c|c|c|c|}
\hline \multirow[b]{2}{*}{ Correlation of facial expression } & \multicolumn{3}{|c|}{ Gestational age } \\
\hline & 30-31 weeks & 32-35 weeks & 36-40 weeks* \\
\hline Mouthing vs. Yawning & $r=0.449 p=0.024$ & NS & $r=0.303 p=0.048$ \\
\hline Mouthing vs. Similing & NS & $r=0.356 p=0.019$ & NS \\
\hline Mouthing vs. Tongue expulsion & $r=0.506 p=0.010$ & NS & $\begin{array}{l}r=0.615 \\
p=0.00001\end{array}$ \\
\hline Mouthing vs. Scowling & NS & NS & NS \\
\hline Mouthing vs. Sucking & NS & NS & NS \\
\hline Mouthing vs. Blinking & NS & NS & $r=0.395 p=0.008$ \\
\hline Yawning vs. Smiling & NS & NS & NS \\
\hline Yawning vs. Tongue expulsion & NS & $r=0.489 p=0.001$ & NS \\
\hline Yawning vs. Scowling & NS & NS & NS \\
\hline Yawning vs. Sucking & NS & NS & $r=0.312 p=0.042$ \\
\hline Yawning vs. Blinking & NS & NS & NS \\
\hline Smiling vs. Tongue expulsion & NS & NS & $r=0.374 p=0.0133$ \\
\hline Smiling vs. Scowling & NS & NS & $p=0.045$ \\
\hline Smiling vs. Sucking & NS & NS & $r=0.351 p=0.021$ \\
\hline Smiling vs. Blinking & NS & NS & NS \\
\hline Tongue expulsion vs. Scowling & NS & NS & $r=0.374 p=0.0136$ \\
\hline Tongue expulsion vs. Sucking & NS & NS & $r=0.533 p=0.0002$ \\
\hline Tongue expulsion vs. Blinking & NS & NS & NS \\
\hline Scowling vs. Sucking & NS & NS & NS \\
\hline Scowling vs. Blinking & NS & NS & NS \\
\hline Sucking vs. Blinking & NS & NS & NS \\
\hline
\end{tabular}

NS, not significant; ${ }^{*}, p=0.009$

significant correlations between facial expressions in different gestational age groups. Further studies with a larger sample size are needed to clarify theontogeny of various fetal facial expressions and their relationships during pregnancy.

\section{CONCLUSION}

The coordination of different parts of the fetal brain controlling facial expressions become apparent after 36 weeks of gestation because of the mature development of the fetal brain and CNS.

\section{REFERENCES}

1. Prechtl HF. Qualitative changes of spontaneous movements in fetus and preterm infant are a marker of neurological dysfunction. Early Hum Dev. 1990 Sep; 23(3): 151-158.

2. Prechtl HF. State of the art of a new functional assessment of the young nervous system: an early predictor of cerebral palsy. Early Hum Dev 1997 Nov; 50(1): 1-11.

3. Prechtl HF. Is neurological assessment of the fetus possible? Eur J Obstet Gynecol Reprod Biol 1997 Dec; 75(1): 81-84.

4. Kurjak A, Azumendi G, Andonotopo W, Salihagic-Kadic A. Three- and four-dimensional ultrasonography for the structural and functional evaluation of the fetal face. Am J Obstet Gynecol 2007 Jan; 196(1): 16-28.
5. Bosma JF. Anatomic and physiologic development of the speech apparatus. Towers DB, editor. Human Communication and its Disorder.Vol. III Raven: New York. 1975; 469-481.

6. Reissland N, Francis B, Mason J, Lincoln K. Do Facial Expressions Develop before Birth? PLoS One 2011 Aug; 6 (8): e24081.

7. AboEllail MAM, Kanenishi K, Mori N, Mohamed OAK, Hata T. 4D ultrasound study of fetal facial expressions in the third trimester of pregnancy. J Matern Fetal Neonatal Med 2018 Jul:31(14); 1856-1864.

8. Bland JM, Altman DG. Statistical methods for assessing agreement between two methods of clinical measurement. Lancet 1986 Feb;1(18476):307-310.

9. Kurjak A, Stanojevic M, Andonotopo W, Salihagic-Kadic A, Carrera JM, Azumendi G. Behavioral pattern continuity from prenatal to postnatal life-A study by four-dimensional (4D) ultrasonography. J Perinat Med 2005 Jun; 32(4):346353.

10. Kurjak A, Azumendi G, Vecek N, Kupešic S, Solak M, Varga D, Chervenak F. Fetal hand movements and facial expression in normal pregnancy studied by four-dimensional sonography. J Perinat Med 2003 Nov; 31(6): 496-508.

11. Hata T, Kanenishi K. Akiyama M, Tanaka H, Kimura K. Realtime 3-D sonographic observation of fetal facial expression. J Obstet Gynaecol Res 2005 Aug; 31(4): 337-340.

12. Yigiter AB, Kavak ZN. Normal standards of fetal behavior assessed by four-dimensional sonography. J Matern Fetal Neonatal Med 2006 Nov; 19(11):707-721. 
13. Yan F, Dai SY, Akther N, Kuno A, Yanagihara T, Hata T. Fourdimensional sonographic assessment of fetal facial expression early in the third trimester. Int J Gynecol Obstet 2006 Aug; 94(2):108-113.

14. Kurjak A, Andonotopo W, Hafner T, Salihagic Kadic A, Stanojevic M, Azumendi G, Ahmed B, Carrera JM, Troyano JM. Normal standards for fetal neurobehavioral developments Longitudinal quantification by four-dimensional sonography. J Perinat Med 2006 Jan; 34(1): 56-65.

15. Kurjak A, Stanojevic M, Azumendi G, Carrera JM. The potential of four-dimensional (4D) ultrasonography in the assessment of fetal awareness. J Perinat Med 2005 Jun; 33(1): 46-53.

16. Lebit DF, Vladareanu PD. The role of $4 \mathrm{D}$ ultrasound in the assessment of fetal behaviour. Maedica (Buchar) 2011 April; 6(2):120-127.

17. Sato M, Kanenishi K, Hanaoka U, Noguchi J, Marumo G, Hata T. 4D ultrasound study of fetal facial expressions at 20-24 weeks of gestation. Int J Gynecol Obstet 2014 Sep; 126(3): 275-279.

18. Kanenishi K, Hanaoka U, Noguchi J, Marumo G, Hata T. 4D ultrasound evaluation of fetal facial expressions during the latter stages of the second trimester. Int J Gynecol Obstet 2013 Jun; 121(3): 257-260.

19. Hata T, Dai SY, Marumo G. Ultrasound for evaluation of fetal neurobehavioural development: from 2-D to 4-D ultrasound. Inf Child Dev 2010 Jan; 19(1): 99-118.

20. Reissland N, Austen JM, Hanaoka U, AboEllail MAM, Uematsu R, Hata T. The potential use of the Fetal Observable Movement System in clinical practice. Donald School J Ultrasound Obstet Gynecol 2015 Jan; 9(4): 426-433.

21. Stiles J, Jernigan T. The basics of brain development. Neuropsychol Rev 2010 Nov; 20 (4): 327-348.
22. Innocenti GM, Price DJ. Exuberance in the development of cortical networks. Nat Rev Neurosci 2005 Dec; 6(12): 955-965.

23. Nijhuis JG, Prechtl HFR, Martin CB, Boots RSGM. Are there behavioural states in the human fetus? Early Hum Dev 1982 Apr; 6(2): 177-195.

24. Roodenberg PJ, Wladimiroff JW, van Es A, Prechtl HFR. Classification and quantitative aspects of fetal movements during the second half of normal pregnancy. Early Hum Dev 1990 Jan-Feb; 25(1): 19-35.

25. Inoue M, Koyanagi T, Nakahara H, Hara K, Hori E, Nakano H. Functional development of human eye movement in utero assessed quantitatively with real-time ultrasound. Am J Obstet Gynecol 1986 Jul; 155(1): 170-174.

26. Horimoto N, Koyanagi T, Nagata S, Nakahara H, Nakano H. Concurrence of mouthing movement and rapid eye movement/non-rapid eye movement phases with advance in gestation of the human fetus. Am J Obstet Gynecol 1989 Aug; 161(2): 344-351.

27. Koyanagi T, Horimoto N, Takashima T, Satoh S, Maeda H, Nakano H. Ontogenesis of ultradian rhythm in the human fetus, observed through the alteration of eye movement and no eye movement periods. J Reprod Inf Psychol1993 Feb; 11(3): 129-134.

28. Grant-Beuttler M, Glynn LM, Salisbury AL, Davis EP, Holliday C, Sandman CA. Development of fetal movement between 26 and 36-weeks' gestation in response to vibro-acoustic stimulation. Front Psychol 2011 Dec; 350(2): 1-7.

29. Reissland N, Francis B, Mason J (2013b). Can healthy fetuses show facial expression of "pain" or "distress"? PLoS ONE 2013 Jun; 8 (6): e65530. 